Bangladesh J. Zool. 48(2): 465-472, 2020

\title{
FLIGHT MUSCLE AND FLIGHT ACTIVITY OF JUNONIA ALMANA (LEPIDOPTERA: NYMPHALIDAE) AND APIS DORSATA (HYMENOPTERA: APIDAE)
}

\author{
Pinakshi Roy, Shanjida Sultana, Tangin Akter, Shefali Begum* \\ and Farhana Ferdousi \\ Department of Zoology, University of Dhaka, Dhaka-1000, Bangladesh
}

Flight ability is a felicity for insects not only to fly around but also to other important purposes like to acquire mates, feed, communicate, defend, disperse and locate host plants (Engel 2015). With this incentive, the present study was conducted to examine the flight activity and flight muscle of Junonia almana (both male and female) butterfly and Apis dorsata worker honey bee at $30 \pm 5^{\circ} \mathrm{C}$ and $75 \% \mathrm{RH}$. By following the tethered flight technique for one hour it was found that among the three (male and female butterfly and honey bee), female butterflies flew more times $(21.65 \pm 5.98 \mathrm{~min})$ compared with others. Similarly, in terms of the measurement (mean length, breadth and volume) of forewing and dorso-longitudinal muscle, female butterfly showed higher value than male butterfly and honey bee.

Butterflies occupy a vital position in the ecosystem by playing role as pollinators of plants promoting genetic diversity and contributing to natural sustainability and for their role as indicators of environmental quality (Reddi et al. 2002). They are called accidental pollinators that unintentionally pick up pollen on their legs and body while perching on flowers to forage for nectar (Boggs and Ross 1993). Butterflies heavily depend on their flight ability to get mates, feed, disperse and locate host plants. Besides chemical defenses and camouflage, adult butterflies rely on their flight ability to avoid predation (Chai and Srygley 1990).

Honey bees play an important role in ecology as pollinators of many plant species. Their products have great commercial importance around the world. They are major agricultural pollinators and are keystone pollinators especially in tropical ecosystems (Suwannapong et al. 2012). Conservation of many habitats depends upon the preservation of bee populations. Reproduction of major elements of flora may be severely limited if the bee population disappear (Michener 2000). Among the castes of honey bee colony, only the worker bees act as forager. Worker honey bees are sterile female. The flight ability of a bee is determined by many factors, including the mass of the bee, the mass of the

*Author for corresponding: <shefali@du.ac.bd>

(C2020 Zoological Society of Bangladesh DOI: https://doi.org/10.3329/bjz.v48i2.52383 
flight muscles, and the power output of the flight muscles. Their flight is totally aerobically supported (Kammer and Heinrich 1978). The large indirect flight muscles of honey bees are used to produce a variety of actions besides flight. These include sonication for pollen collecting, for defense and for compacting soil within nests, all of which possess higher frequencies than flight (Buchmann 1983).

Understanding the importance of butterfly and honey bee and the importance of flight muscle in their life, it is very important to make more study on their flight activity and flight muscle which will help in establishing and maintaining a sustainable healthy ecosystem. Nymphalidae is the dominant butterfly family including 5000 described species (Fres 1989) and among them Junonia almana (the peacock pansy) is very common species in Curzon hall area, University of Dhaka. Apis dorsata (the giant honey bee) is very common species in Curzon hall area. So, the objective of the study was to observe the flight activity and flight muscle of butterfly and honeybee, and to compare these between male and female butterfly.

In this study, Junonia almana butterfly (both male and female) and Apis dorsata honey bee (female) were examined and analyzed to observe their flight performance. Flight activity was associated with the wings. Hind wings are not necessary for flight (Jantzen and Eisner 2008). So, measurements of forewings were taken in this experiment. Dorsal longitudinal muscle (DLM) and flight activity of Junonia almana butterfly and Apis dorsata honey bee were evaluated.

The flight activity was observed by Tethered flight technique which is a very reliable technique for observing flight activity of flying insects. It allows studies of biomechanics and electrophysiology of flight control (Iyengar and Wu 2014). The behavior of flying insects has been investigated in laboratory by scientists over many years. Many studies concerned flight capability or duration and used tethered flight approaches (Hardie 1993). This represents a crude approximation to field flight as the mechano-sensory and visual cues perceived are very different (Dingle 1985).

Flight activity was observed following the Tethered flight technique as suggested by Cooter and Armes (1993) who used there are three tethering techniques traditionally monitor flight performance in insects. This simplest technique, static tethering was used in the which, involves attaching the insects attached to a fixed support, making them fly with a stimulator and then the duration of time of wing beating was recorded. A table fan of about 1200 RPM (rounds per minute) and a table lamp were used as stimulators.

Ten worker honey bees of Apis dorsata, 10 female butterflies and 10 male butterflies of Junonia almana were collected from Curzon hall area, Botanical 


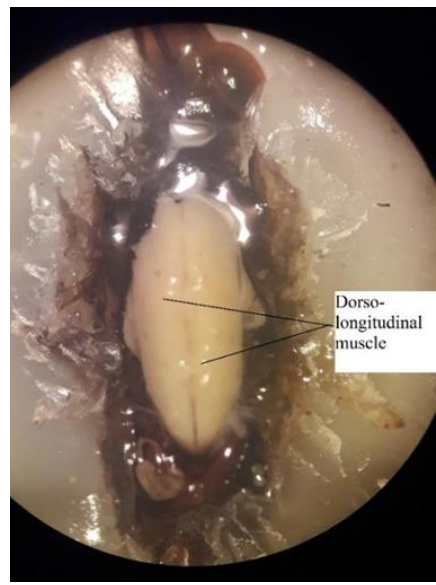

(a)

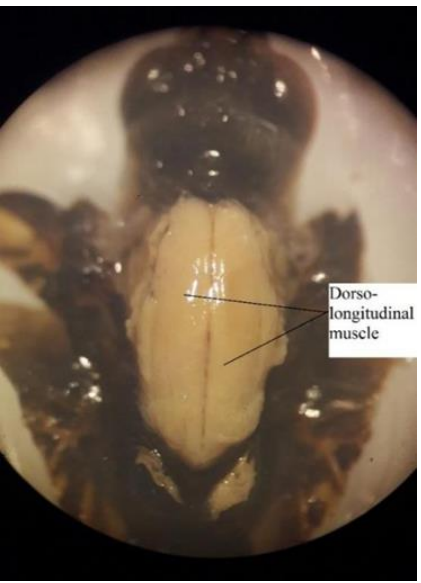

(b)

Fig. 1. Flight muscle of butterflies (a) male butterfly and (b) female butterfly.

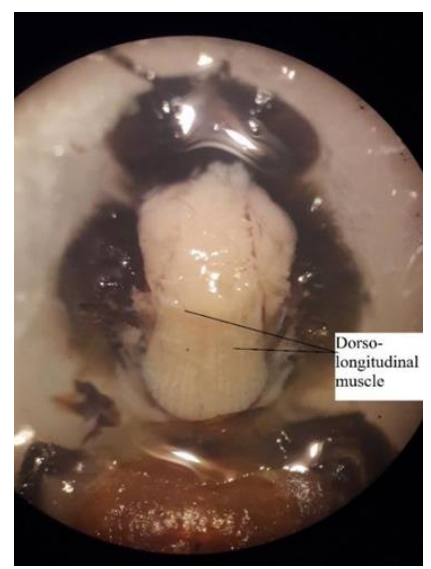

Fig 2. Flight muscle of honey bee.

Table 1. Showing the flight activity of male and female butterfly and honey bee

\begin{tabular}{cccc}
\hline No. of observation (n) & Male butterfly & $\begin{array}{l}\text { Mean } \pm \text { SE (min) } \\
\text { Female butterfly }\end{array}$ & Honeybee \\
\hline 10 & $20.08 \pm 6.2$ & $21.65 \pm 5.98$ & $7.09 \pm 2.7^{*}$ \\
\hline
\end{tabular}

*Significant at $\mathrm{p}=0.05$

Table 2. Showing the measurement of forewing of male and female butterfly and honeybee

\begin{tabular}{clccc}
\hline $\begin{array}{c}\text { No. of } \\
\text { observation (n) }\end{array}$ & Name of observation & Male butterfly & $\begin{array}{c}\text { Mean } \pm \text { SE } \\
\text { Female butterfly }\end{array}$ & Honeybee \\
\hline \multirow{2}{*}{10} & Length of forewing $(\mathrm{mm})$ & $25.7 \pm 0.5$ & $26.8 \pm 0.25$ & $11.9 \pm 0.18$ \\
& Breadth of forewing $(\mathrm{mm})$ & $17.3 \pm 0.37$ & $18 \pm 0.42$ & $4.2 \pm 0.1$ \\
& $\begin{array}{l}\text { Volume of forewing } \\
\text { (mm3) }\end{array}$ & $2033.37 \pm 0.12$ & $2290.27 \pm 0.13$ & $52.91 \pm 3.62$ \\
\hline
\end{tabular}


Table 3. Showing the measurement of flight muscle of male and female butterfly and honeybee.

\begin{tabular}{ccccc}
\hline $\begin{array}{c}\text { No. of } \\
\text { observation (n) }\end{array}$ & Name of observation & \multicolumn{3}{c}{ Mean \pm SE } \\
& Male butterfly & Female butterfly & Honeybee \\
\hline \multirow{2}{*}{10} & Length of DLM (mm) & $4.69 \pm 0.15$ & $4.91 \pm 0.17$ & $4.55 \pm 0.18$ \\
& Breadth of DLM (mm) & $2.15 \pm 0.1$ & $2.42 \pm 0.07$ & $2.48 \pm 0.02$ \\
& Volume of DLM (mm) & $17.64 \pm 1.93$ & $22.84 \pm 1.68$ & $7.26 \pm 0.3$ \\
\hline
\end{tabular}

garden and Animal garden by using sweeping net. The species were identified by following Borror et al. (1976). The collected insects were kept at $-4^{\circ} \mathrm{C}$ in a refrigerator for about 3-4 minutes to make them anesthetized.

For the observation of flight activity of the butterfly and honey bee, a wooden stand with four holes on the upper plate of it was used. The holes were filled with foam and a bamboo stick was set in the wooden stand with the help of foam in the holes. A table fan was set one meter away from the wooden stand. A table lamp was placed on the wooden stand.

The anesthetized butterfly and honey bee were left for a while until these came into sense. Then the fan and the lamp were switched on and the duration of the insect wing beating within one hour was counted with the help of a stopwatch.

The length and width of the forewing of the anesthetized insect were measured with a scale. Then the sample was kept in a vial filled with $70 \%$ alcohol for temporary preservation to observe flight muscle.

Preserved butterflies and honey bees were dissected and the flight muscle was observed through microscope and a picture was taken through it. The length and breadth of the flight muscle were measured by using 'ImageJ' software. Here, $1 \mathrm{~mm}$ was set as scale and after 'analysis' the length and breadth were measured.

Volume of forewing of both butterfly and honey bee and flight muscle of honey bee were conducted by following formula:

$\mathrm{V}=1 / 3 \pi \mathrm{r}^{2} \mathrm{~h}$

Here, $V=$ volume, $\Pi=3.1416, r=$ radius (half of breadth of forewing or flight muscle), $h=$ height (length of forewing or flight muscle).

Volume of flight muscle of butterfly were conducted by following formula:

$\mathrm{V}=\pi \mathrm{r}^{2} \mathrm{~h}$

Here, $V=$ volume, $\Pi=3.1416, r=$ radius (half of breadth of forewing or flight muscle), $\mathrm{h}=$ height (length of flight muscle)

Data were analyzed statistically by calculating mean, standard error and t test. 
The flight activity was observed by Tethered flight technique. In the present study, it was found that the mean time of flight activity of male was 20.08 min and that of female was $21.65 \mathrm{~min}$ (Table 1). It showed that duration of flight activity of female was longer than that of male. The flight activity did not vary significantly between male and female butterfly $(\mathrm{P}>0.05)$.

In this study we found that male butterflies were weak flyer than the female. The flight muscle of female butterfly was stronger than the male. Female butterflies were generally heavier than males and allocate more mass to the abdomen but males allocate more to the thorax (Karlsson and Wickman 1990). Females have fewer flight muscles per unit of body mass than males. Females have to produce more flight force per unit of flight muscle mass than equally performing males do. Because of their heavier abdominal loads, females may operate at nearer to maximum power output (Berrigan 1991). Sharp et al. (1975) conducted an experiment on flight performance of males and females of Bactrocera cucurbitae and $B$. dorsalis (Diptera) and reported that females are larger and better fliers. The maximum distances that individual males of $B$. cucurbitae had flown, were $9845 \mathrm{~m}$ (8 days old) at flight speeds of $96.7 \%$ of the time while the maximum distances that individual females had flown, were $13,000 \mathrm{~m}$ (8 days old) at flight speeds of $98.5 \%$ of time. The flight activity of worker (female) honey bee was compared with that of female butterflies for better understanding (Table 1).

The duration of flight of female butterfly was $21.65 \mathrm{~min}$ and that of honeybee was $7.09 \mathrm{~min}$. It showed that duration of flight activity of female butterfly was significantly $(\mathrm{P}<0.05)$ more than that of honeybee. The butterfly is better flyer than honey bee. Although in general butterflies do not carry as much pollen loads as the bees do (Bashar 2015), they are capable of carrying pollens over greater distances (Goulson et al. 1997). This happens in nature (mostly in the forests) because butterflies visit flowers and plants in all layers of vegetation in an ecosystem (Bashar et al. 2015).

The experiment showed that the mean of length, breadth, and volume of forewing of male butterfly were $25.7 \mathrm{~mm}, 17.3 \mathrm{~mm}$ and $2033.37 \mathrm{~mm} 3(2.03$ $\mathrm{cm} 3$ ), respectively and those of female butterfly were $26.8 \mathrm{~mm}, 18 \mathrm{~mm}$ and $2290.27 \mathrm{~mm} 3(2.29 \mathrm{~cm} 3)$, respectively (Table 2). The mean length of forewing of female was greater than male. The length of forewing did not significantly vary between male and female butterfly $(\mathrm{P}>0.05)$. The mean breadth of forewing of female was greater than male. The breadth of forewing did not vary significantly between female and male butterfly ( $\mathrm{P}>0.05)$. The mean volume of forewing of female was greater than that of male. The volume of forewing did not significantly vary between female and male butterfly $(\mathrm{P}>0.05)$. 
Apparently, the wings of honey bee are quite smaller than butterfly. The mean of length, breadth and volume of forewing of honey bee were $11.9 \mathrm{~mm}, 4.2 \mathrm{~mm}$ and $52.91 \mathrm{~mm} 3$ (0.05 cm3), respectively (Table 2).

Dorso-longitudinal muscle (DLM) was observed as it is the chief flight muscle. The measurements were taken by 'ImageJ' software. The DLM of butterflies were cylindrical shaped (plate 1). The mean of length, breadth and volume of DLM of male butterfly were $4.69 \mathrm{~mm}, 2.15 \mathrm{~mm}$ and $17.64 \mathrm{~mm} 3(0.02 \mathrm{~cm} 3)$ respectively, and those of female were $4.91 \mathrm{~mm}, 2.42 \mathrm{~mm}$ and $22.84 \mathrm{~mm} 3(0.02 \mathrm{~cm} 3)$, respectively (Table 3). It was showed that mean length of DLM in female was greater than male. The length of DLM did not significantly $(P>0.05)$ vary between female and male butterfly. The mean breadth of DLM of female was greater than male. The breadth of DLM did not significantly vary (P>0.05) between female and male butterfly. The mean volume of DLM of female was greater than that of male. The volume of DLM did not significantly vary $(\mathrm{P}>0.05)$ between female and male butterfly.

The experiment showed that mean of length, breadth and volume of DLM of honey bee were $4.55 \mathrm{~mm}, 2.48 \mathrm{~mm}$ and $7.26 \mathrm{~mm} 3(0.007 \mathrm{~cm} 3)$, respectively (Table 3). The DLM of honey bees are conical shaped (plate 2).

Flight muscles are the most metabolically active tissue in insects, rendering flight one of the most energetically demanding activities (Nijhout 1994). It is known that in some insect species, even in the absence of flight, flight muscle maintenance can be energetically demanding (Mole and Zera 1994). In spite of the flight being energetically expensive, it is required for the majority of adult activities in flying insects (Chown and Nicolson 2004).

In female insects another reason may be oogenesis-flight syndrome which means the development of the ovaries and development of flight apparatus are physiologically antagonistic processes and their interplay affects migration in a quantitative way (Johnson 1963). Some scientists reported that oogenesis- flight syndrome is not applicable to some species. Schumacher et al. (1997) studied on long flights in Cydia pornonella (Lepidoptera: Tortricidae) and showed that mated females had peak flight capacity between 1 and 3 days after eclosion, which corresponded with the major egg-laying period.

Flight is important for both butterfly and honey bee as it increases the range over which food, partners and suitable habitat for breeding can be found and also encourage long distance migration, courtship and male-male contests. So, the study on their flight activity and flight muscle may contribute to their conservation, indirectly conservation of ecosystem. 


\section{LITERATURE CITED}

BASHAR, M.A., KHAN, H.R., RAHMAN, S., CHOWDHURY, E.K., ALAM, M.M. and MOULA, G. 2015. Wildlife conservation through butterfly colonization. J. Biodivers. Conserv. Bioresour. Manag. 1(1): 71-82.

BASHAR, M.A. 2015. Butterflies of Bangladesh: A broad approach to nature lovers (EBBL Red List and Butterfly activities). Vol. 2. BCTF Publications, Dhaka-1000. 177 pp.

BERRIGAN, D. 1991. Lift production in the Flesh Fly, Neobellieria (= Sarcophaga) bullata Parker. Funct. Ecol. 5: 448-456.

BOGGS, C.L. and ROSS, C.L. 1993. The effect of adult food limitation on life history traits in Speyeria mormonta (Lepidoptera: Nymphalidae). Ecology. 74: 433-441.

BORROR, D.J., DELONG, D.M. and TRIPLEHORN, C.A. 1976. An Introduction to the Study of Insects. Holt, Rinehart and Winston, USA. 852 pp.

BUCHMANN, S. L. 1983. Buzz pollination in angiosperms. In Handbook of Experimental Pollination Biology. JONES, C. E. and R. J. LITTLE (eds). New York: Van Nostrand Reinhold. 73-113 pp.

CHAI, P. and SRYGLEY, R. B. 1990. Predation and the flight, morphology, and temperature of Neotropical rainforest butterflies. Am. Nat. 135: 748-765.

CHOWN, S. and NICOLSON, S. 2004. Insect physiological ecology: mechanisms and patterns. Oxford University Press, Oxford. 254 pp.

COOTER, R. J. and ARMES, N. J. 1993. Tethered flight technique for monitoring the flight performance of Helicoverpa armigera (Lepidoptera: Noctuidae). Environ. Entomol. 22(2): 339345.

DINGLE, H. 1985. Migration. pp. 375-415. In: KERKUT, G. A. and GILBERT, L. I. (eds.) Comprehensive insect Physiology, Biochemistry and Pharmacology. Vol. 9. Pergamon Press, Oxford, $735 \mathrm{pp}$.

ENGEL, M.S. 2015. Insect evolution. Current biology. 25(19): 868-872.

FRES, P.S. 1989. The Illustrated Encyclopedia of the Butterfly World. Salamander Books Ltd. 275 pp.

GOULSON, D., OLLERTON, J. and SLUMAN, C. 1997. Foraging strategies in the small skipper butterfly, Thymelicus flavus: when to switch? Anim. Behav. 53: 1009-1016.

HARDIE, J. 1993. Flight behavior in migrating insects. J. Agric. Entomol. 10(4): 239-245.

IYENGAR, A. and WU, C.F. 2014. Flight and seizure motor patterns in Drosophila mutants: simultaneous acoustic and electrophysiological recordings of wing beats and flight muscle activity. J. Neurogenetics. 28(3-4): 316-328.

JANTZEN, B. and EISNER, T. 2008. Hindwings are unnecessary for flight but essential for execution of normal evasive flight in Lepidoptera. PNAS. 105(43): 16636-16640.

JOHNSON, C. G. 1963. Physiological factors in insect migration by flight. Nature. 198(4879): 423427.

KAMMER, A. E. and HEINRICH, B. 1978. Insect flight metabolism. Adv. Insect Physiol. 13: 133-228. 
KARLSSON, B. and WICKMAN, P.O. 1990. Increase in reproductive effort as explained by body size and resource allocation in the speckled wood butterfly, Pararge aegeria (L.). Funct. Ecol. 4: 609617.

MICHENER, C.D. 2000. The bees of the world. Johns Hopkins University Press, Baltimore. 992 pp.

MOLE, S. and ZERA, A.J. 1994. Differential resource consumption obviates a potential fight fecundity trade-off in the sand cricket (Gryllus wrmus). Funct. Ecol. 8: 573-580.

NIJHOUT, F.H. 1994. Insect hormones. Princeton University Press, Princeton. 280 pp.

REDDI, C.S., ATLURI, J.B., RAMANA, S.P.V., SAMATHA, B., RAMESH, L. and JYOTSNA, U.V.V. 2002. Andhra University campus - A butterfly paradise. Bulletin of Andhra University Research Forum. 8(8): 26-28.

SCHUMACHER, P., WEYENETH, A., WEBERS, D.C. and DORN, S. 1997. Long flights in Cydia pornonella L. (Lepidoptera: Tortricidae) measured by a flight mill: influence of sex, mated status and age. Physiol. Entomol. 22: 149-160.

SHARP, J.L., DERRELL, L., CHAMBERS and HARAMOTO, F.H. 1975. Flight mill and stroboscopic studies of Oriental Fruit Flies and Melon Flies, including observations of Mediterranean Fruit Flies. Hawaiian Entomol. Soc. 22(1): 137-144.

SUWANNAPONG, G., EIRI, D.M. and BENBOW, M.E. 2012. Honeybee communication and pollination. pp. 39-62. In: New Perspectives in Plant Protection. A.R. Bandani (ed.). InTech. 246 pp.

(Manuscript received on 14 February, 2020 revised on 15 December, 2020) 